Cahiers $d u$ MONDE RUSSE

\section{Cahiers du monde russe}

Russie - Empire russe - Union soviétique et États indépendants

45/3-4 | 2004

Varia

\title{
Antioh Kantemir, Russko-francuzskij slovar' Antioha Kantemira
}

\section{Stefan Lemny}

\section{OpenEdition}

\section{Journals}

Édition électronique

URL : https://journals.openedition.org/monderusse/4180

DOI : $10.4000 /$ monderusse. 4180

ISSN : $1777-5388$

Éditeur

Éditions de l'EHESS

Édition imprimée

Date de publication : 1 juillet 2004

Pagination : 639-642

ISBN : 2-7132-2009-2

ISSN : $1252-6576$

Référence électronique

Stefan Lemny, "Antioh Kantemir, Russko-francuzskij slovar' Antioha Kantemira », Cahiers du monde russe [En ligne], 45/3-4 | 2004, mis en ligne le 16 juin 2009, consulté le 03 septembre 2022. URL

http://journals.openedition.org/monderusse/4180 ; DOI : https://doi.org/10.4000/monderusse.4180

Ce document a été généré automatiquement le 3 septembre 2022

Tous droits réservés 


\title{
Antioh Kantemir, Russko- francuzskij slovar' Antioha Kantemira
}

\author{
Stefan Lemny
}

\section{RÉFÉRENCE}

Antioh KANTEMIR, Russko-francuzskij slovar' Antioha Kantemira (Dictionnaire russe-français). T. 1 : A-O, t. 2 : P-U. Introd. et édition: Elizaveta B ABAEVA. Moscou, Jazyki slavjanskoj kul'tury, 2004, LII-1309 p.

1 Les biographes ont parlé depuis longtemps du Dictionnaire russe-français d'Antioche Kantemir, sans savoir si l'ouvrage existait réellement ou s'il s'était perdu comme tant d'autres œuvres du passé. Dans la première édition de ses Satires, publié en 1749, en français (bien avant l'édition russe de 1762), le préfacier, dont l'identité reste controversée (pour certains auteurs, ce serait l'abbé Guasco, pour d'autres, Henri Gross, le secrétaire de Kantemir), mentionne que l'auteur «avait commencé un Dictionnaire Russien \& Français qui n'est pas fini ».

Des témoignages publiés ultérieurement ont enrichi cette information. La correspondance du poète révèle par exemple qu'il était vivement préoccupé en 1737 par ce projet : de Londres, où il se trouvait en tant qu'ambassadeur de Russie, il demande des livres à ses anciens professeurs Ilinskij et Christophe Frédéric Gross (frère de son secrétaire), en espérant tirer de cette manière " quelques lumières » pour l'avancement de son travail ${ }^{1}$.

3 En revanche, rien ne perce à ce sujet durant les années où Kantemir est ambassadeur à Paris, de 1738 à $1744^{2}$, année de sa mort. Seul le catalogue de ses œuvres, rédigé après son décès, mentionne curieusement un « Dictionnaire russe et français » dont on a supposé à juste titre que ce serait celui d'Antioche Kantemir, puisque, effectivement, aucun autre ouvrage portant le même titre n'existait à cette date. 
C'est presque tout ce que l'on pouvait dire sur le dictionnaire du poète jusqu'à la découverte d'un précieux manuscrit grâce aux recherches perspicaces de Bronislava Gradova, spécialiste des manuscrits de Kantemir à la Bibliothèque nationale de SaintPétersbourg ${ }^{3}$. Les études qu'elle a publiées à cette occasion donnent un premier aperçu sur un dictionnaire français-russe (il faut noter la différence du titre par rapport au dictionnaire russe-français mentionné ci-dessus) que l'auteur a rédigé à SaintPétersbourg, lorsqu'il était inscrit comme auditeur à l'Académie russe des sciences, inaugurée peu de temps auparavant. La précision est tirée de la page d'un manuscrit qui indique "l'année 1725-1726 de la naissance de Jésus » et contient en outre une mention sur la destination de l'ouvrage : « en faveur et à l'usage de ce [sic] qui veut apprendre la langue française ».

5 Elizaveta Babaeva, chercheur à l'Institut de langue russe de l'Académie russe de Moscou, propose à présent une nouvelle contribution fondamentale à la connaissance de l'œuvre d'Antioche Kantemir, en publiant une solide édition du dictionnaire russe et français sous forme de deux volumes épais, bien reliés, portant sur la couverture un autoportrait délicat de l'auteur, selon une peinture qui constitue une autre découverte récente de Bronislava Gradova ${ }^{4}$.

6 Grâce à cette édition, les spécialistes disposent de l'intégralité du dictionnaire resté inachevé. Le texte se présente en deux colonnes, l'une contenant les mots russes, rangés alphabétiquement, l'autre, leur traduction en français, le tout accompagné en bas de page de précisions de l'éditeur concernant le texte. Un énorme matériel lexicographique est ainsi offert à l'attention des chercheurs.

7 L'introduction (Elizaveta Babaeva) propose une première approche éclairante en fournissant des détails sur l'aventure du manuscrit. Considéré longtemps comme perdu, celui-ci est conservé actuellement dans la collection Durov de la Bibliothèque d'État de Russie (ancienne Bibliothèque Lénine), après être passé entre les mains de plusieurs propriétaires successifs. Le manuscrit est relié en 3 tomes, comportant au total 1379 feuilles et 47105 notices. Pour la plus grande partie, le texte est écrit de la même main, selon toute vraisemblance sous la dictée de l'auteur (à partir de 1737, celui-ci a été confronté à de sérieux troubles de la vue), et porte de temps en temps ses corrections autographes.

8 L'introduction met particulièrement en évidence l'importance lexicographique du dictionnaire. «L'histoire des conceptions lexicologiques du XVIIIe siècle - écrit Elizaveta Babaeva - ne connaît pas le nom d'Antioche Kantemir: il n'a pas écrit de traités spécialisés consacrés exclusivement aux problèmes de la langue russe ou au langage, contrairement à ses contemporains russes comme Vasilij Tredjakovskij ou Vasilij Adodurov. La contribution d'Antioche Kantemir à la construction de la Russie postpétrovienne comme poète, traducteur, théoricien de la littérature s'accompagne certainement d'une réflexion sur la langue, mais on doit reconstruire ses conceptions sur tel ou tel problème linguistique à partir d'un certain nombre de remarques isolées, éparpillées dans des commentaires enfouis dans différents textes. Le dictionnaire qui est publié ici est un énorme travail lexicologique de très grande valeur pour l'étude de la pratique et des conceptions linguistiques de Kantemir. Ce premier dictionnaire russefrançais conçu par le poète et diplomate russe présente un intérêt incontestable pour l'histoire de la lexicographie russe et européenne ».

9 Le catalogue déjà cité de la bibliothèque de Kantemir mentionne quelques dictionnaires dont l'auteur aurait pu se servir dans son travail. En poussant plus loin l'analyse 
comparative de ces dictionnaires avec l'ouvrage du poète, l'éditrice tire plusieurs conclusions dignes d'intérêt. C'est le cas de l'influence exercée sur son projet par le dictionnaire slavo-gréco-latin de Polykarpov (1704), seul dictionnaire russe alors imprimé et offrant une liste classée de termes russes. La preuve en est, souligne Elizaveta Babaeva, que $84 \%$ des termes du dictionnaire de Polykarpov se trouvent dans le dictionnaire de Kantemir (p. xxxvII). Or, par ce fait, l'auteur du dictionnaire russe et français se rallie à l'autorité incontestable de son modèle qui avait parfaitement compris et adopté la norme « slavonne ecclésiastique » de la période postérieure aux réformes du patriarche Nikon, responsable du schisme des vieux-croyants, en jouant un rôle important de fixation pratique et fiable de la langue russe écrite. Il faut noter, en outre, que la grammaire slavo-russe dont disposait Kantemir était celle qui avait été éditée en 1723 par Maksimov, élève comme Polykarpov des frères Lihuda, qui avaient dirigé et animé l'école gréco-slavo-latine de Moscou, que Kantemir a fréquentée peu de temps vers 1719.

En dépit de son ancrage dans la tradition slavonne et religieuse, l'entreprise lexicographique de Kantemir est aussi un clin d'œil de l'auteur vers l'esprit de son temps. Elizaveta Babaeva souligne par exemple la place qu'occupe dans son dictionnaire le vocabulaire se référant à l'amour, qui témoigne d'une laïcisation galante et courtisane. Elle remarque également chez Kantemir une certaine différence d'appréciation par rapport à Polykarpov quant à l'importance de l'orthographe qui rend la position du premier plus souple, en accord avec les besoins de l'écriture laïque.

11 Cette piste d'interprétations lexicographiques n'est qu'une facette de l'intérêt que peut susciter le dictionnaire d'un poète connu également comme l'un des traducteurs les plus éminents de son temps (notamment du français). On lui doit par exemple les traductions de la Lettre d'un Sicilien à un de ses amis, selon l'édition de Chambéry, 1710; du Tableau de Cébès; de quelques Satires et du Discours au roi de Boileau (bien que cette traduction reste controversée), des Entretiens sur la pluralité des mondes de Fontenelle, ou du livre Le newtonianisme pour les dames d'Algarotti (manuscrit encore non identifié). On pourrait se demander dans quelle mesure ces traductions ont eu des conséquences directes sur la rédaction du dictionnaire.

Mais une certitude se dégage. Par ses proportions considérables, le dictionnaire offre l'image de l'impressionnante capacité de travail de son auteur. L'ouvrage n'est pas terminé : si le premier volume a seulement quelques taches blanches dans la traduction du russe en français, dans le deuxième volume, qui commence avec la lettre « $\mathrm{P}$ », cela devient la règle : seuls quelques mots russes sont traduits ici et là !

Il reste aussi à déterminer le rapport qui existe entre le dictionnaire russe-français publié par Elizaveta Babaeva et le français-russe signalé par Bronislava Gradova. Et il est permis d'espérer que l'édition présente fera place à d'autres interrogations qui conduiront vers une meilleure connaissance de l'auteur des Satires.

14 En tout cas, l'édition de l'œuvre d'Antioche Kantemir s'enrichit d'un titre de référence après les éditions publiées en 1867-1868 et en $1956^{5}$. 


\section{NOTES}

1. L. N. Maikov, Materialy dlja biografii kn. A. D. Kantemira, Saint-Pétersbourg, 1903, p. 86.

2. Marcelle Ehrhard, Un ambassadeur de Russie à la cour de Louis XV. Le Prince Cantemir à Paris (1738-1744), Paris, Les Belles lettres, 1938 (Annales de l'Université de Lyon).

3. B. A. Gradova, «Pervye perevody Antioha Kantemira ", in Issledovanija pamjatnikov pis'mennoj kul'tury $v$ sobranijah $i$ arhivah otd. rukop. $i$ redkih knig, Saint-Pétersbourg, 1985, p. 46-57; id., «A. D. Kantemir - sostavitel' pervogo russko-francuzskogo slovarja », in Maria Di Salvo, Lindsey Hughes, eds., A window on Russia. Papers from the V International Conference of the Study Group on Eighteenth-Century Russia, Gargnano, 1994, La Fenice, 1996, p. 155-159.

4. B. A. Gradova, « Neizvestnyj portret A. D. Kantemira », dans T'epolo i ital'janskaja živopis' XVIII veka $v$ kontekste evropejskoj kul'tury, Saint-Pétersbourg, Gosudarstvennyj Ermitaž, 1996, p. 18-19.

5. Sočinenija, pis'ma i izbrannye perevody knjazja Antioha Dmitrieviča Kantemira, ed.: P. A. Efremov ; introd. : V. Ja. Stojunin, I-II, SPb, I. I. Glazunov, 1867-1868 ; Antioh Kantemir, Sobranie stihotvorenij, Leningrad, 1956.

Nos remerciements vont à Nicolas Plagne qui a traduit l'introduction de l'édition présentée ici. 